\title{
Energy Simulation of Marine Currents through Wind Tunnel with use the Haar Wavelet for Electromagnetic Brake Systems
}

\author{
Aldo A. Belardi, Antônio H. Piccinini \\ Centro Universitario da FEI \\ Av. Humberto de Alencar Castelo Branco, $\mathrm{n}^{\circ} 3972$, \\ 09850-901, Sao Bernardo do Campo, SP, Brasil
}

Received: January 22, 2021. Revised: March 13, 2021. Accepted: March 17, 2021. Published: March 26, 2021.

\begin{abstract}
A demand clean and renewable energy through the use of submerged turbines. Using this new source of energy we can grow the production of electrical energy in a sustainable way. This paper presents the simulation of maritime currents using a wind tunnel which allows the comparison of speed variations of water compared to air. It also features a brake system that uses a magnetic sensor in real time using the wavelets. As an example, it can be the ones mentioned concerning the feedback control system applied in a brand WEG motor of 100 hp with 2 poles $3500 \mathrm{rpm}$ rotation. Using software tools, the Acquired data are post-processed.
\end{abstract}

Key words: Tidal Energy, Marine Currents, Wavelets

\section{INTRODUCTION}

$\mathrm{E}_{\mathrm{n}}$ nergy is a major constituent of modern society. It is necessary to create goods based on natural resources and to provide many of the services with which we have benefited. Energy is a basic concept in all disciplines of science and engineering. At around all the different decades forms of generation have been researched and used. Global demand for energy has tripled in the past 50 years and may triple in the next 30 years. With this growth in consumption along with the scarcity of current resources and non-renewable, the company was forced to seek new alternatives for the future of energy supply. Alternative energy, renewable, are new prospects for energy resources. We are learning to use different sources of energy photovoltaic, hydro, wind, thermal and sea. The marine current turbines are energy conversion mechanisms that leverage the movement of water caused by tides to move. Resulting from interaction with the fluid the turbine blades come into rotational motion transmitting power to the shaft to which it is coupled. In turn, the shaft, which may or may not be connected to a gearbox, a generator operates and produces energy [1].

The blades of a turbine marine surfaces serve as sustaining forces capable of producing and sustaining appreciable considerably larger than the forces of resistance. Among the various processes for production of renewable two mentioned are very similar with regard to conversion technology used: wind and sea current energy. In these processes are used turbines that are driven turbo machinery which convert kinetic energy of the fluid in which they are immersed into mechanical energy and being coupled to a generator into electrical power. The technology applied to the systems of marine current follows the same basic principles of wind turbines, with the main difference is the density of the fluid passing through the turbine, since water is about 800 times denser than air. This factor makes marine turbines have several potential advantages over wind turbines and other renewable energy technologies, including: Production of greater potencies for rotors of similar size to a wind turbine caused by the higher load factors exercised by the water. The current velocity does not depend on climatic factors, since the tides are caused mainly by the rise and fall of water bodies resulting from the gravitational interaction between the earth, moon and sun, and predictable throughout the year such as the amount energy that can be extracted. Therefore, it is possible to build simpler systems without complex mechanisms that prevent destruction braking unit in case of a sudden increase in fluid velocity [2].

\section{FORMULATION}

\section{A. Tidal Power}

Tidal energy is derived from the gravitational forces of attraction that operate between a molecule on the earth and moon, and between a molecule on the earth and sun. As the earth rotates, the distance between the molecule and the moon will vary. When the molecule is on the dayside of the earth relative to the moon or sun, the distance between the molecule and the attracting body is less than when the molecule is on the horizon, and the molecule will have a tendency to move away from the earth. Conversely, when the molecule is on the night side of the earth, the distance is greater and the molecule will again have a tendency to move away from the earth. The separating force thereby experiences two maxima each day due to the attracting body. It is also necessary to take into the account the beating effect caused firstly by difference in the fundamental periods of the moon- and sun-related gravitational effects, which creates the so called spring and neap tides, and secondly the different types of oscillatory response affecting different seas. If the sea surface were in static equilibrium with no oscillatory effects, lunar forces, which are stronger than solar forces, would produce tidal range that would be approximately only $5.34 \mathrm{~cm}$ high[3]. 


\section{B. Stream Turbines}

Stream turbines make use of the kinetic energy of the tidal stream or ocean stream (river stream can also be exploited with the same technology) by using both propeller type horizontal axis turbines and vertical axis ones. Therefore they are different from conventional hydraulic turbines used for dams, which mainly use the potential energy due to high hydraulic heads and pressure by employing high solidity, i.e. their turbine blades cover most of the water flow passages. Stream turbines cannot do so because they operate in free stream conditions, thus they have to have relatively low solidity and at the same time, as large rotors areas as possible to capture the energy in the flow with low pressure and low velocity.

\section{Marine Current Turbines}

Marine current turbines are developing twin horizontal axis two bladed turbines. The currently has limited the feasible installation sites to have spring peak current velocity of $>2$ $\mathrm{m} / \mathrm{s}$ and with a depth of $20 \mathrm{~m}$ to $40 \mathrm{~m}$. We have successfully installed a $300 \mathrm{~kW}$ prototype off the coast of Lynmouth which has been in operation since $16 / 6 / 03$, dumping power into a load bank. Following successful installation and operation in Strangford, the next stage will be a semi-commercial venture with the installation of about 10 turbines at a site which has not yet been announced according to figure 1 .

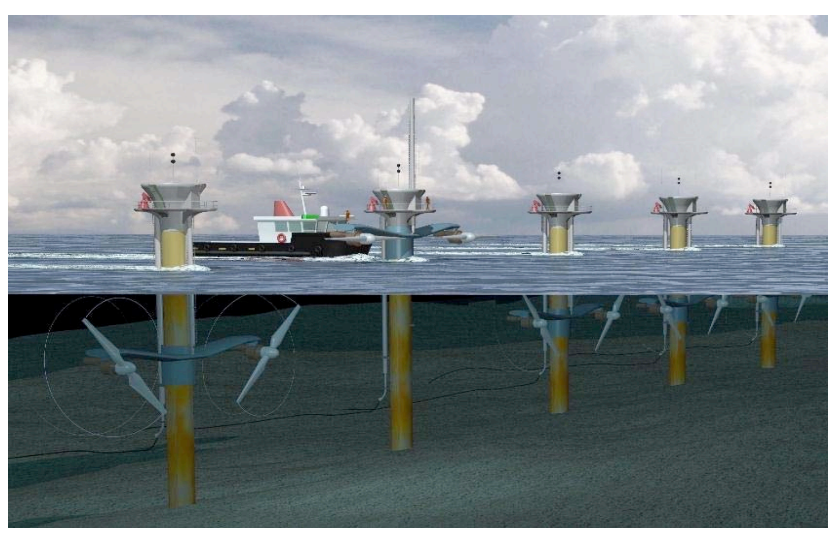

Fig. 1. The current system design for a 1.2 MW system to be located in Strangford Lough.

The prototype off the coast of Lynmouth was found to produce better energy conversion efficiency than expected. The model used to predict energy output was based on a wind turbine model which has a maximum theoretical efficiency of 0.59 known as the Betz limit. The Betz limit is dependent on the velocity difference between the front and rear of the turbine. The energy contained in the flow (wind or tidal) is[4]:

$$
\mathrm{E}=\frac{1}{2} \rho \mathrm{V}^{2} \mathrm{E}_{\mathrm{k}}=\frac{1}{2} \mathrm{mV}^{2}
$$

where $\mathrm{E}_{\text {area }}=$ Energy per unit area, $\mathrm{E}_{\mathrm{k}}=$ Kinetic energy per unit volume, $\mathrm{m}=$ mass, $\mathrm{V}=$ velocity before the turbine $\rho=$ density. By contrast with wind turbines of similar output the high power densities achieved with streams of flowing water at the velocities encountered mean that large horizontal thrust forces are applied to marine turbines. The power available per square meter of sea surface.

$$
\mathrm{P}=\frac{1}{2} \rho \mathrm{hk}_{\mathrm{s}} \mathrm{k}_{\mathrm{n}} \mathrm{k}_{\mathrm{ef}} \mathrm{V}^{3}
$$

where $\mathrm{h}=$ water depth, $\mathrm{k}_{\mathrm{s}}=$ Daily availability factor $(0.424), \mathrm{k}_{\mathrm{n}}$ $=$ neap $/$ spring availability factor $(0.57) \mathrm{k}_{\mathrm{ef}}=$ efficiency, $\mathrm{V}=$ max. current velocity.

\section{Determination of Power Output}

According to the literature the general power available per square meter can be determined according to Eq.(2).

Including $\mathrm{k}_{\mathrm{s}}$ and $\mathrm{k}_{\mathrm{n}}$ will give the average power output over both spring neap cycle and over a daily cycle. The efficiency of the TED can also be included to appreciate the total amount of energy available at any given location. However the TEDs cannot be installed infinitely close behind and in front of each other because there is a need to enable the tidal current to both recover in velocity behind them and return to a laminar. The area seen by each turbine row:

$$
\left(\frac{\pi}{4}\right)(h-c) \delta x
$$

where $\mathrm{h}=$ water depth, $\mathrm{c}=$ blade clearance depth, $\delta \mathrm{x}=$ width of the grid square, assumed length of the row

The number of rows in each grid square depends on the spacing between each row. However an estimate was made to use 15 blade diameters between each row. The number of turbine rows per square:

$$
\text { Numbers of rows }=\frac{\delta y}{2 \mathrm{rs}}
$$

where $\delta y=$ breadth of the grid squares, $r=$ the turbine radius, $s$ = spacing in blade diameters.

It is therefore, possible to determine the number of rows of turbines in each grid square, and hence the area by the turbines in each grid square. The number of turbine rows per square:

$$
\left(\frac{\pi}{4}\right)(\mathrm{h}-\mathrm{c}) \delta \mathrm{x}\left(\frac{\delta}{2 \mathrm{rs}}\right)
$$


Power output for a given grid square can be determined as follows:

$$
\mathrm{P}=\frac{1}{2} \rho \mathrm{Ak}_{\mathrm{s}} \mathrm{k}_{\mathrm{n}} \mathrm{k}_{\mathrm{ef}} \mathrm{V}^{3}
$$

where $\mathrm{A}=$ Area seen by turbines, within the square

However the values of $\mathrm{k}_{\mathrm{s}}$ and $\mathrm{k}_{\mathrm{n}}$ were tested against values calculated from the verified model output and were found to vary according to location. Therefore when determining the power output from each grid square for the resource assessment these values were dropped and an approximation of the velocity was used to calculate the power at 15 min time steps throughout a spring neap cycle. The tidal velocity also varies according to the spring neap cycle over a period of 14.75 days. The method of determining an approximate tidal velocity for each square at any given time.

$$
\begin{aligned}
\mathrm{V}_{\mathrm{sn}} & =\left(\mathrm{V}_{\mathrm{s}}-\mathrm{V}_{\mathrm{n}}\right) \sin \left(\frac{2 \pi(24 \phi+\mathrm{T})}{14.75}\right) \\
\mathrm{V}_{\mathrm{t}} & =\left(\mathrm{V}_{\mathrm{s}}-\left|\mathrm{V}_{\mathrm{n}}\right|\right) \sin \left(\frac{2 \pi(\mathrm{T}+\phi)}{12.4224}\right)
\end{aligned}
$$

Where $\mathrm{V}_{\mathrm{sn}}=$ Velocity according to a spring neap cycle, $\mathrm{V}_{\mathrm{t}}=$ Velocity according to a spring neap cycle and the semi-diurnal cycle, $\mathrm{V}_{\mathrm{s}}=$ Maximum velocity during a spring, de $\mathrm{Vn}=$ Maximum velocity during a neap tide, $\Phi=$ The tidal phase difference and $\mathrm{T}=$ Time (hours from start time of model data). The total tidal generation at any given time can be established, taking into account the different tidal phases between the squares with the use of the array given above. Although the average tidal phase is given for the group when selecting which generators to remove the individual tidal phase is used to calculate the total tidal generation at a given time [5].

\section{APPLICATION}

We use the transfer methodology of obtaining the energy through wind power in the energy drawn from the sea currents. Taking account of the difference between the two means of obtaining energy equals the ratio between the relative densities of the media under consideration. To estimate the values that we could get in marine turbine systems, taking into account the proportions ideas and a turbine equivalent to a wind turbine, we base this work in order to estimate potential energy.

Typical values for the components when the efficiency of the turbine is operating at its nominal conditions are as follows: The efficiency with which the turbine extracts kinetic energy of the incoming stream is approximately 45\%. For water flowing through a turbine for extracting the maximum efficiency occurs when the flow velocity in the rotor face is reduced to $1 / 3$ in relation to the free stream velocity, which provides a good extraction efficiency of 16/27 (=59\%), which is the so-called "Lanchester Betz limit". The efficiency with which the energy extracted from the stream is delivered to the generator is $96 \%$. Losses at this stage include friction within the gearbox usually used to accelerate the rotational speed of the turbine rotor (slower) rotational speed of the generator (fast). The losses represent approximately 5\% are due to friction and mechanical energy dissipated as heat [6]. Taking these efficiency criteria have an approximate representation of the reality of energy a turbine generator. For generating an air flow in order to provide measurements generated by a turbine, the wind tunnel used prepared in our laboratories from the center of mechanical engineering. The equipment is called generator of an air flow in a concentrated area delimited enabling approximate calculations of natural reality.

The tunnel is based on a cylindrical tube where we have a 5 HP motor concentrate $(3.728 \mathrm{KW})$. The dimensions of the tunnel are approximately $60 \mathrm{~cm}$ in diameter with an extension of $5 \mathrm{mts}$ thus the fluid (air) passes through the tube and is forced by the engine passes the test box which is expressed later in this article. The air flow at the turbine outlet has a maximum speed of approximately $32 \mathrm{~m} / \mathrm{s}$ at $1280 \mathrm{rpm}$. The figure 2 we show the equipment used.

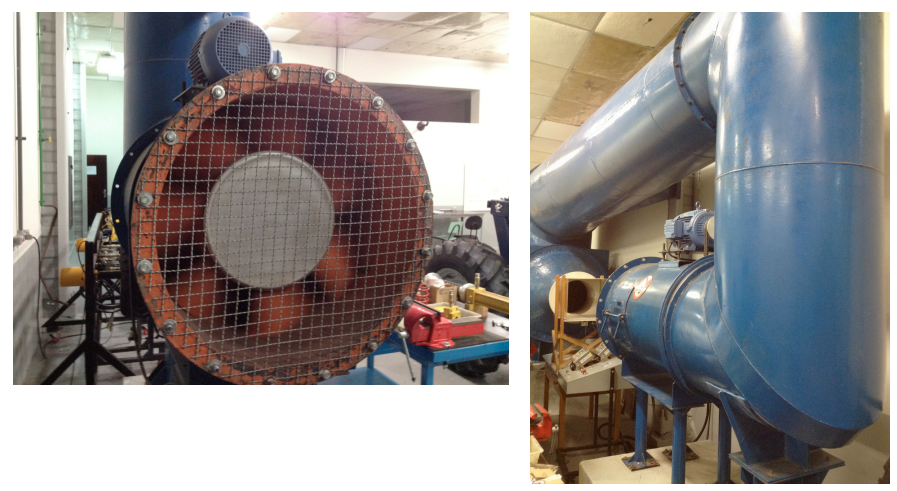

Fig.2. The wind tunnel

Using the method of energy transfer through the fluid (air water), relative density, we have the force generated from the force exerted by the fluid under study only depends on its density, its speed, the area absorbed by the generator.

Thus we can use this theoretical foundation to generate signals and execute forms of security, magnetic brake system for the generation of energy through currents maritime. For the system of the proposed system we use the brake wavelet analyze. So we will analyze the signals through the method, and thus can create a form of magnetic brake. The stator current evaluation is carried out using the signal acquired by a current sensor. It should be mentioned that, for this propose, the related magnetic field can also be evaluated.

The signal of the current sensor is converted for digital into regular intervals of time. Using the Matlab, Simulink and a analog-to-digital conversion board, the variation of the coefficients of the transformed signal by the Haar wavelets are computed in real time, verifying the instant where we got some type of disturbance in the process, as for example one tool in addition or a joining in the axle. 
In figure 3 we present in form of diagram of blocks, the acquisition method that converts and processes the developed system [7].

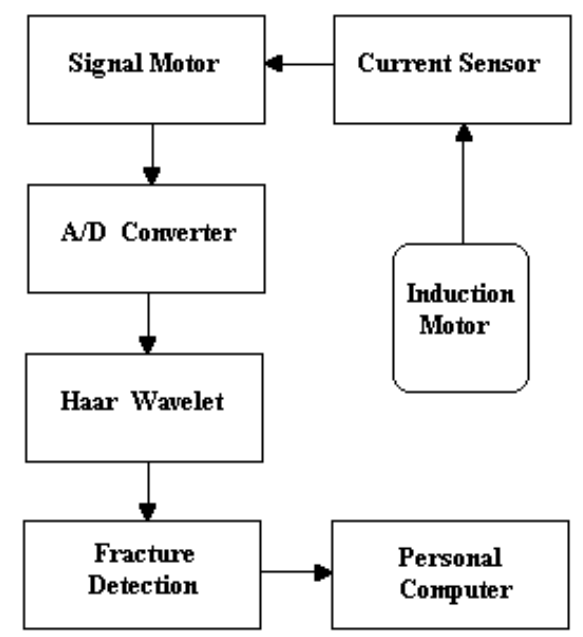

Fig.3. System of data acquisition

Normally the electric engines are composites for two components: the separate stator and the rotor for a small called interval "gap". The phase tensions are applied in the stator causing a current field. These currents provoke a rotation in the magnetic field that puts into motion the rotor in one determined direction [8][9]. The speed of rotation of the magnetic field is called synchronism speed ns (rpm) and normally can be represented by the relation of frequency (f) of the stator (Hertz) and by the number of poles for each phase of the motor. In milling machines, the breaking of cutting tools can cause deformations on the rest of the machine. Normally, this phenomenon is caused by an extreme increasing force in the cutting pieces laterals. This effect will be the increasing in the current, as well as the torque increasing will be the dissipate power in the motor. The current of the motor can be gotten, by multiplying the signal of the output for the value of the shunt resistance $(10 \Omega / 25 \mathrm{~W})$, for each one of the phases in accordance with figure 4 .

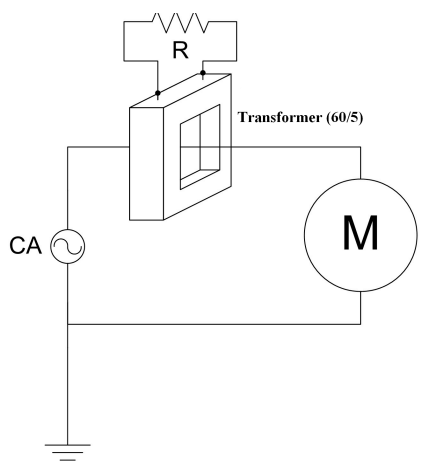

Fig.4. Measuring the current of the motor
The current in the electric engine can be calculated in agreement with the following:

$$
I=\frac{V_{R}}{R} \times \frac{60}{5} \times \frac{1}{N}
$$

The signal of the output tension then is sent for a board installed in the computer, which makes the conversion of the analogical signal to digital. The interface between the signal and the board in the computer is made through a digital to analogical converter of high performance, installed in the computer that allows the communication with the Simulink in real time [10].

The figure 5 shows the Simulink equivalent block diagram that was developed.

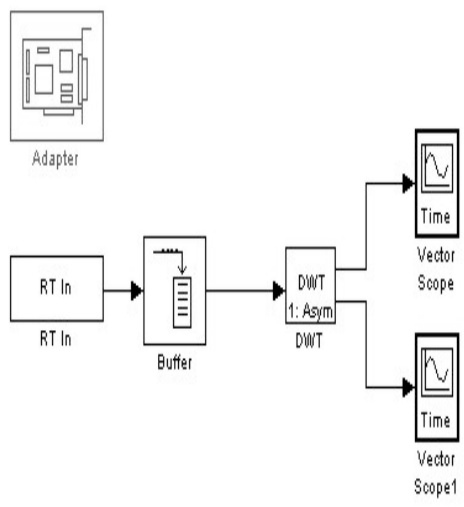

Fig.5. Example of Simulink block diagram

The block "Adapter" is used for the acquisition of the data, not intervening with the signal of the model. It also serves to help in the functioning of block "RT" that has as out, the signal received from the data acquisition board. In this block, it is possible also to configure the sampling time of the signal and the number of used input. The block "DWT" carries through transformed discrete of the wavelet input signal, that will be a size vector in the input, so respecting dyadic intervals. It also allows selecting the family of wavelets and the used level number, and the analysis of vectors and the coefficients, grouped in form of matrices. Finally the block "Scope", that allows graphically showing the signals of the entrance and outputting [11].

\section{RESULTS}

With the lifting of the data generated through the wind tunnel, we have the following propositions. The variation of engine power is transferred proportionally to its rotation, from this structure we have the following data obtained by wind tunnel. The marked difference in power density of water compared to that of wind, however, may be seen from Table 1 for various velocities assuming a density for salt water of $1030 \mathrm{~kg} / \mathrm{m} 3$ and an air density of $1.2473 \mathrm{~kg} / \mathrm{m} 3$ corresponding to air at $10{ }^{\circ} \mathrm{C}$. 


\section{TABLE I}

Relative power densities of marine currents and air at different velocities.

\begin{tabular}{ccc}
\hline \hline $\begin{array}{c}\text { Velocity } \\
(\mathrm{m} / \mathrm{s})\end{array}$ & $\begin{array}{c}\text { Power Density } \\
\text { Marine } \\
\left(\mathrm{KW} / \mathrm{m}^{2}\right)\end{array}$ & $\begin{array}{c}\text { Power Density } \\
\text { Wind } \\
\left(\mathrm{KW} / \mathrm{m}^{2}\right)\end{array}$ \\
\hline 1 & 0.52 & - \\
2 & 4.12 & - \\
3 & 13.91 & 0.2 \\
10 & - & 0.62 \\
15 & - & 2.10 \\
20 & - & 4.99 \\
\hline \hline
\end{tabular}

The pressure on the spot remained at $1.1 \mathrm{~kg} / \mathrm{m}^{3}$, a variation of approximately $10 \%$ of the pressure used in the studies presented the temperature stayed $19.1{ }^{\circ} \mathrm{C}$. These characteristics are due to climatic factors and the height of where the experiment was conducted. Thus if we calculate the proportion of energy generated by these data, transferring the data to a maritime environment, we have to evaluate its relative density, the fact that the same speed of $2 \mathrm{~m} / \mathrm{s}$ in water can generate about $4 \mathrm{~kW} / \mathrm{m}^{2}$, and taking into account the wind turbines would have to spend a wind flow of approximately 20 $\mathrm{m} / \mathrm{s}$. This is caused by the much lower density of air $(1.225$ $\mathrm{kg} / \mathrm{m}^{3}$ at sea level), relative to water $(1024 \mathrm{~kg} / \mathrm{m} 3$ for sea water), wind speeds of 9.3 to $11.8 \mathrm{~m} / \mathrm{s}$ are needed to achieve the same energy density of wind turbines. The area used was the area of the wind tunnel test, considering a small turbine with approximately an area $\mathrm{A}=0.450 \mathrm{~m}$ (width) $\mathrm{x} 0.425 \mathrm{~m}$ (height). Totaling an area of approximately $\mathrm{A}=0.1912 \mathrm{~m}^{2}$. Due to the size of the minimized area of evidence, we have the values were lower than the actual size according to Table II.

TABLE II

Power generated through the mathematical model.

\begin{tabular}{ccccc}
\hline \hline $\begin{array}{c}\text { Rotation } \\
(\mathrm{rpm})\end{array}$ & $\begin{array}{c}\text { Velocity } \\
\text { relative } \\
(\mathrm{m} / \mathrm{s})\end{array}$ & $\begin{array}{c}\text { Power } \\
\text { Provided } \\
(\mathrm{KW})\end{array}$ & $\begin{array}{c}\text { Power } \\
\text { Density } \\
\text { Marine } \\
(\mathrm{KW})\end{array}$ & $\begin{array}{c}\text { Power } \\
\text { Density } \\
\text { Wind } \\
(\mathrm{KW})\end{array}$ \\
\hline 100 & 2,5 & 0,28 & 0,87 & 0,00 \\
200 & 5 & 0,57 & 6,97 & 0,01 \\
300 & 7,5 & 0,86 & 23,52 & 0,02 \\
400 & 10 & 1,15 & 55,74 & 0,06 \\
500 & 12,5 & 1,44 & 108,87 & 0,11 \\
600 & 15 & 1,73 & 188,13 & 0,19 \\
700 & 17,5 & 2,02 & 298,74 & 0,30 \\
800 & 20 & 2,31 & 445,93 & 0,45 \\
900 & 22,5 & 2,6 & 634,93 & 0,64
\end{tabular}

Thus the actual value has a greater proportion however only one difference between sizes of prototypes is. Thus we can generate studies in small prototypes using air as a medium, and thus transform the results to water. Thus far we use the signals mathematically performed to study magnetic brake. For the brake system the results had been acquired for the easiness if also gets the data in real time and for the easiness of the coupling, with the computerized system.

The figure. 6 and 7 presents the signal of the current of the motor in unloaded and in loaded the discrete transformed one into the signal, the approaching coefficients.

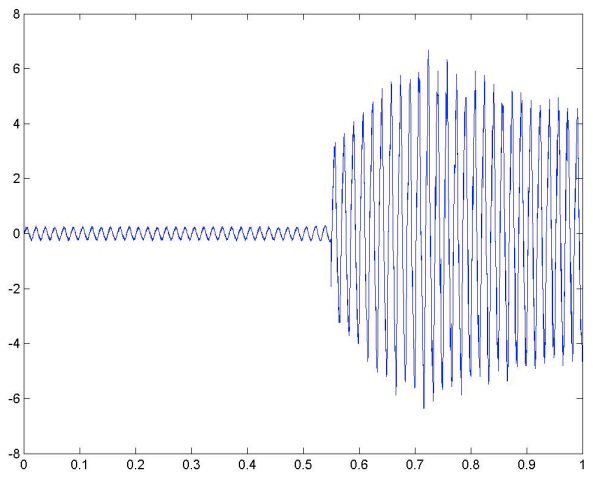


Fig. 6. Signal of the current in the stator

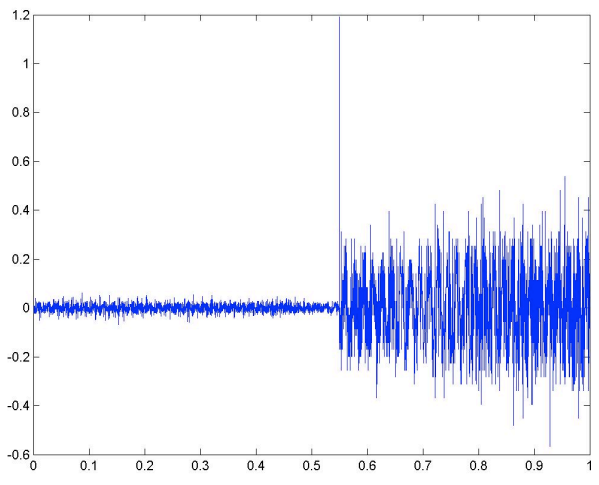

Fig. 7. Coefficient of details using wavelet of Haar level 1

The figure 8 presents the signal of the current in the stator of the rotating equipment identified in the graph for "s". The peaks of the current level had been gotten using it electrical rotating equipment machine in unloaded and load. Applying the discrete transformed one into signal "s", using the wavelet de Haar with resolution level 1, we got the coefficients of approach represented in the graph "a" and the coefficients of details represented in " $\mathbf{d}_{\mathbf{1}}$ ".

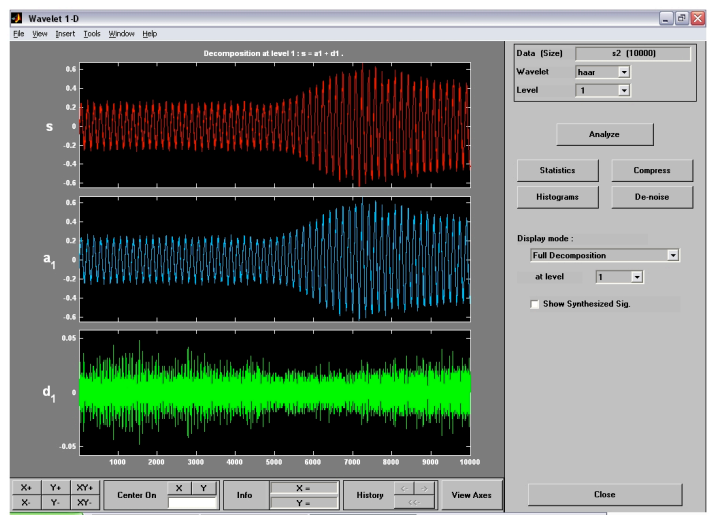

Fig. 8. Current in the stator in unloaded and load

Applying the discrete transformed one into signal "s", using the Haar wavelet with resolution level 1, we got the coefficients of approaching represented in the graph "al" and the coefficients of details represented in "d1". The coefficient of details using wavelet of Haar level one [12][13][14].

The figure 9 shows, from the top to bottom, the peak current level signal, and the coefficients regarding the first level of resolution using wavelet of Haar, and the details and the discontinuity ones that are related to stator current increase behavior, in real time.

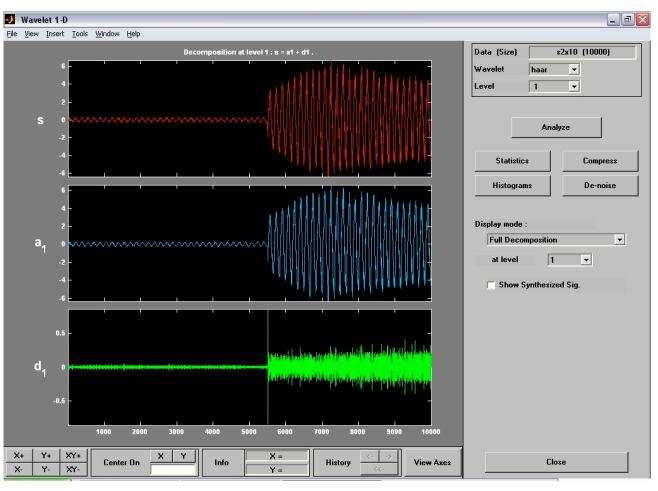

Fig.9. Current in the stator in unloaded and load

Those coefficients were obtained considering the unloaded and loaded motor conditions.

One aspect to be emphasized is the ones concerning the signal conditioning requirements due to the inherent noisy present in the machine process.

The amplitude of the output signal can be modified, and a proper approaching should be applied to take it into consideration.

In the instant where the current in the stator increases quickly with torque, the cutting section in addition to the system, causes a discontinuity that is detected by the approaching coefficients. The stator current signal, considering the unloaded and loaded charge operation and the break at $0.55 \mathrm{~s}$.

\section{CONCLUSION}

This study present a methodology capable of recognizing and designing a model that can represent marine turbines in another way, being made from physically modeled equations from mathematical models and theories of fluid mechanics. It was possible the measurement of the calculation in a theoretical environment, structuring possible applied work in building a prototype to make this technology commercially viable in order to minimize impacts ambient in power generation today. As for the brake system proposed methodology can be used to detect faults in other media generators of electricity, where the kinetic force is employed in the process. The great advantage of the use of the magnetic sensor is that beyond not having consuming, the time of reply with the use of wavelets of Haar is extremely fast $(<0.55 \mathrm{~s})$ 


\section{ACKNOWLEDGMENT}

The authors are grateful to the University Center of FEI by the availability of materials and laboratories with adequate infrastructure for academic research and professional assistance at all levels.

\section{REFERENCES}

[1] Hinrichrhs R. A., Kleinbach M., Reis L. B, Energia e Meio Ambiente, Cengage Learning, São Paulo, 2010.

[2] Bryans A. G., Impacts of Tidal Stream Devices on Electrical Power Systems, Belfast, 2006.

[3] Hammons T. J., Tidal Energy, Vol 81, N 3, March 1993.

[4]Fraenkel, P.L., Power from Marine Currents, Proceedings of the Institution of Mechanical Engineers, Part A, Journal of Power and Energy, Vol. 216, pp. 1-14. ISSN: 09576509, 2002.

[5]Tidal Power, A Factfile provided by The Institution of Engineering and Technology, Irland, 2007.

[6] Fraenkel P.L., Power from Marine Currents Journal of Power and Energy,vol.216,pp. 1-14,2002.

[7]Wright,M. , Sea Flow Tidal Current Turbine. Watts Conference, London, March, 2004.

[8]Li, X. Detection of tool flute breakage in end milling using feedmotor current signatures, IEEE/ASME Transactions on Mechatronics, Vol. 6, N 4, pp. 491- 498, 2001.

[9]Skogestad, S.; Postlethwaite, I. Multivariable Feedback Control: Analysis and Design. New York, John Wiley, 1996.

[10]Kim, G.D.; Chu, C.N. In-Process Tool Fracture Monitoring in Face Milling Using Spindle Motor Current and Tool Fracture Index, The International Journal of Advanced Manufacturing Technology Vol. 18, N 6, pp. 383-389, 2001.

[11]Palm, W., Introduction to Matlab 7 and Simulink for Engineers, McGraw-Hill, pp. 55-97, 2003.

[121]Belardi A. A. ,Cardoso J. R., Sartori C. F., Wavelets Application in Electrostatic and their Computing Aspects, Electric and Magnetic Fields, EMF 2009, Italy, pp. 43-46,2009.

[13]D. E. Newland, Random Vibrations Spectral and Wavelet Analysis, Addison Wesley Longman, pp. 315-333,1993.

[14]Aboufadel E.; Schlicker S., Discovering Wavelets, John Wiley \& Sons, pp. 1-42, 1999.

\section{Creative Commons Attribution License 4.0 (Attribution 4.0 International, CC BY 4.0)}

This article is published under the terms of the Creative Commons Attribution License 4.0

https://creativecommons.org/licenses/by/4.0/deed.en_US 